Thorax (1974), 29, 522.

\title{
Effect of fulvine on pulmonary arteries and veins of the rat
}

\author{
C. A. W A G E N VOR T, N. WA G E N VOOR T, \\ a n d H. J. D I J K \\ Department of Pathological Anatomy, Wilhelmina Gasthuis, \\ University of Amsterdam, The Netherlands
}

\begin{abstract}
Wagenvoort, C. A., Wagenvoort, N., and Dijk, H. J. (1974). Thorax, 29, 522-529. Effect of fulvine on pulmonary arteries and veins of the rat. Fulvine, one of the pyrrolizidine alkaloids from the Crotalaria group, was administered to rats in a single dose. Vasoconstriction and medial hypertrophy of pulmonary arteries and right ventricular hypertrophy developed gradually, starting after one week. Smooth muscle fibres developed in the arterial adventitia. Fibrinoid necrosis and arteritis of these arteries were common. In addition, however, changes were observed in pulmonary veins and venules which showed thickening of their walls by constriction, proliferation of muscle fibres, and increase of collagen, leading to luminal occlusion. Apparently fulvine is angiotoxic not only for pulmonary arteries but also for pulmonary veins. This detracts from the usefulness of fulvine in the experimental production of pulmonary arterial hypertension.
\end{abstract}

The toxicity of various species of the plant family Crotalaria for animals has long been recognized. Bras, Berry, and György (1957) demonstrated that alkaloids from Crotalaria fulva, as components of West Indian bush-tea, were responsible for the development of veno-occlusive disease of the liver. Lalich and Merkow (1961) noted that ingestion of the seeds of Crotalaria spectabilis produced pulmonary arterial lesions in rats.

Since that time various workers have studied the effect of ingestion of Crotalaria seeds or of administration of the Crotalaria alkaloids on the pulmonary vasculature. The vascular lesions produced in this way in the lungs of rats were confined to the pulmonary arteries and arterioles. Swelling of the endothelium, vasoconstriction, medial hypertrophy, and necrotizing arteritis are among the most conspicuous features (Kay and Heath, 1969). Significant changes in the pulmonary veins and venules have not been described, and the experiment with Crotalaria or its alkaloids has been suggested as a model for pulmonary arterial hypertension (Stötzer, Herbst, Reichl, and Köllmer, 1972). Our observation that fulvine administered to rats induces severe changes not only in pulmonary arteries but also in pulmonary veins was the reason for the present study.

\section{MATERIAL AND METHODS}

We used 62 female albino Wistar rats, approximately six to seven weeks of age and weighing from 140 to 170 grams at the beginning of the experiment. Ful vine was administered to 50 rats, either orally or intras peritoneally, as a single dose of respectively 80 and $50 \mathrm{mg}$ per $\mathrm{kg}$ body weight. The 12 other rats werex kept as controls. The weights of all the animals were noted weekly.

The animals were killed with ether at interval varying from one to six weeks after fulvine applicaß tion. Four rats were killed after one week, three afteo two, four after three, 10 after four, 10 after five, and seven after six weeks. One rat died spontaneousl $b$ after five weeks and 11 after approximately six. weeks.

The control rats were also killed at the same intervals. Necropsy was performed as soon after death as possible and special attention was given to the heart lung specimen and the liver. The hearts were opened and after the blood had been removed the free wall of the right ventricle was dissected and weighed, as was the left ventricle with the attached ventriculap? septum. The ratio of the weight of the left ventricle including the septum, to that of the right ventricle was used as an assessment of possible right ventriculat hypertrophy.

Small blocks of lung tissue were immediately fixe for electron microscopic studies, which are reported in the following paper (Wagenvoort, Dingemans, and 
Lotgering, 1974). The remainder of the lungs was fixed in buffered formalin $10 \%$ and embedded in paraffin. Sections cut at $7 \mu \mathrm{m}$ were stained with haematoxylin and eosin, Lawson's elastic stain counterstained with van Gieson's stain, Perl's iron stain, and toluidine blue at a $\mathrm{pH}$ of 1.6 for mast cells. In addition the phosphotungstic acid haematoxylin stain for demonstration of fibrin was used.

Sections stained for elastic tissue were studied morphometrically. The media of 25 muscular pulmonary arteries in each animal was measured and expressed as a percentage of the external diameter. An average ratio for the medial thickness in each rat was thus obtained.

Uninterrupted serial sections were made from the lung tissue of 12 rats in order to identify small arterioles and venules by tracing them back to larger and easily recognizable vessels. This was particularly important when severe changes were present in these small vessels.

Mast cells in 50 high-power fields of sections stained with toluidine blue were counted in each rat. Subsequently, after assessing the area represented by these 50 high-power fields, the number of mast cells was converted to their number per square millimetre.

\section{RESULTS}

During the first week following the application of fulvine, the rats failed to grow. After the first week the animals gained weight gradually until after three to four weeks they again showed loss of weight (Fig. 1) with increasing dyspnoea and malaise. Then their condition rapidly deteriorated and those rats which were not killed died spontaneously, usually after five to six weeks.

NECROPSY FINDINGS In the four rats killed after one week the gross findings at necropsy were limited to the liver, which showed marked haemorrhage and varying degrees of focal necrosis.

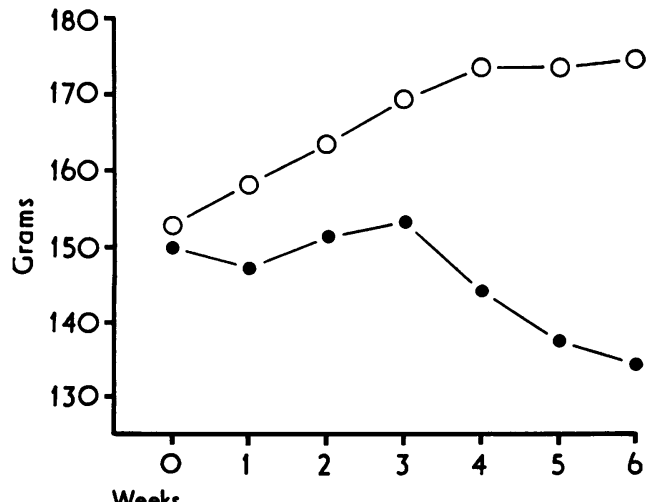

FIG. 1. Average weight of test rats (๑) as compared to control rats (O).
In animals surviving the application of fulvine for a longer period, the liver was usually dark and congested but there was no necrosis. On the other hand, in these rats the main gross findings were in the thoracic cavity. Particularly in those surviving for four weeks or more, the lungs generally showed varying degrees of haemorrhage and oedema, sometimes accompanied by pleurat effusions.

Right ventricular hypertrophy was a constant finding in rats surviving the application of fulvine. This is indicated by a decreasing ratio between the weight of the left ventricular wall, including the ventricular septum, and that of the free right ventricular wall. This index varied in normal controls from 3.03 to 4.55 with an average of 4.02 . In rats after fulvine application, there was a gradual decrease in this ratio during the first four weeks and thereafter it remained constant at a value between 1 and 2.5 (Fig. 2).

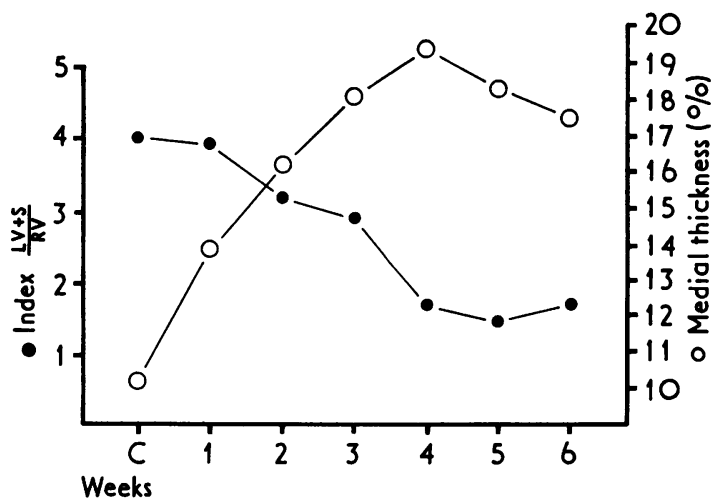

FIG. 2. Average index of ratio of left ventricle, including ventricular septum, to right ventricle (๑) and average medial thickness of muscular pulmonary arteries and arterioles $(\mathrm{O})$ in control rats $(\mathrm{C})$ and in test rats during the experiment.

HISTOLOGICAL EXAMINATION There were various changes in the lung tissue and in the pulmonary vessels. In the lung parenchyma, foci of bronchopneumonia and parabronchial accumulations of lymphocytes or polymorphonuclear leucocytes were regularly present in the test rats. In some of the control rats small and insignificant foci of lymphocytes adjacent to bronchial walls were observed but bronchopneumonia did not occur in this group.

Pulmonary oedema, interstitial oedema, and varying degrees of haemorrhage were an almost constant finding in test rats surviving the application for four weeks or more. Deposition of iron 
pigment was usually mild to moderate but in some cases severe.

Mast cells generally were normal in number in the first two weeks but increased after three weeks and very sharply from the fourth week onward. Their number per square millimetre in the control rats was $0 \cdot 8$, after one week $2 \cdot 2$, after two weeks 0.6 , and after three weeks 72 . Subsequently, after four to six weeks, their numbers rose respectively to 323,430 , and 382 .

As compared to control animals, which have fairly thin-walled pulmonary arteries (Fig. 3), the

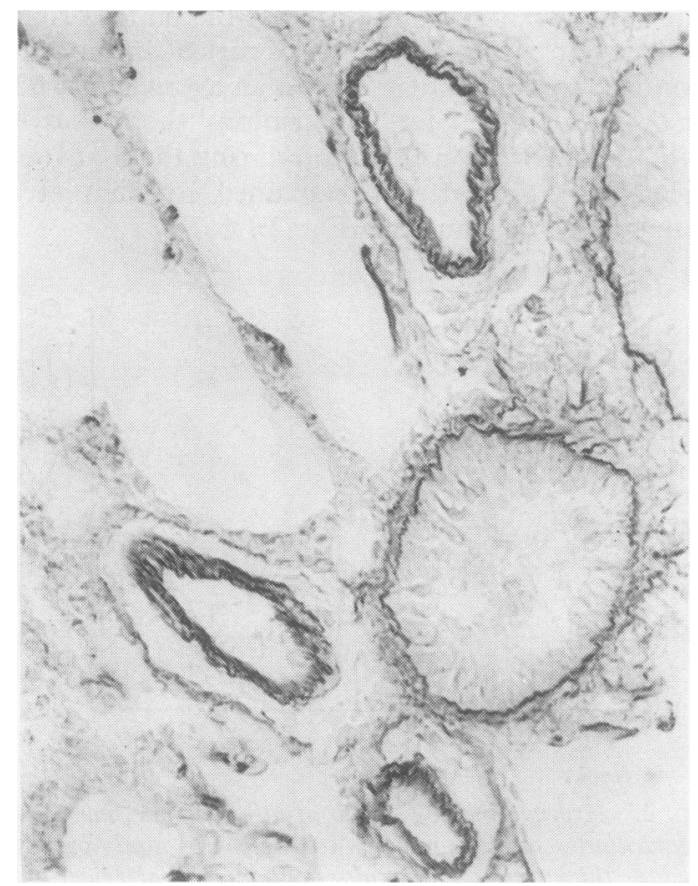

FIG. 3. Normal muscular pulmonary arteries of control rat with fairly thin media (Elastic van Gieson $\times 350$ ).

muscular pulmonary arteries and arterioles of the test rats during the first three weeks do not show marked changes except for a gradual increase of pulmonary arterial medial thickness. This becomes apparent from the result of morphometric assessment (Fig. 2). From the very marked crenation of the internal elastic lamina and the narrow lumen of the muscular pulmonary arteries and arterioles (Fig. 4) it was deduced that vasoconstriction plays a part in the increased thickness of the vascular wall. In these arteries the endothelial layer is often prominent and the endothelial cells, by swelling and vacuolization of their cytoplasm, protrude into the lumen.

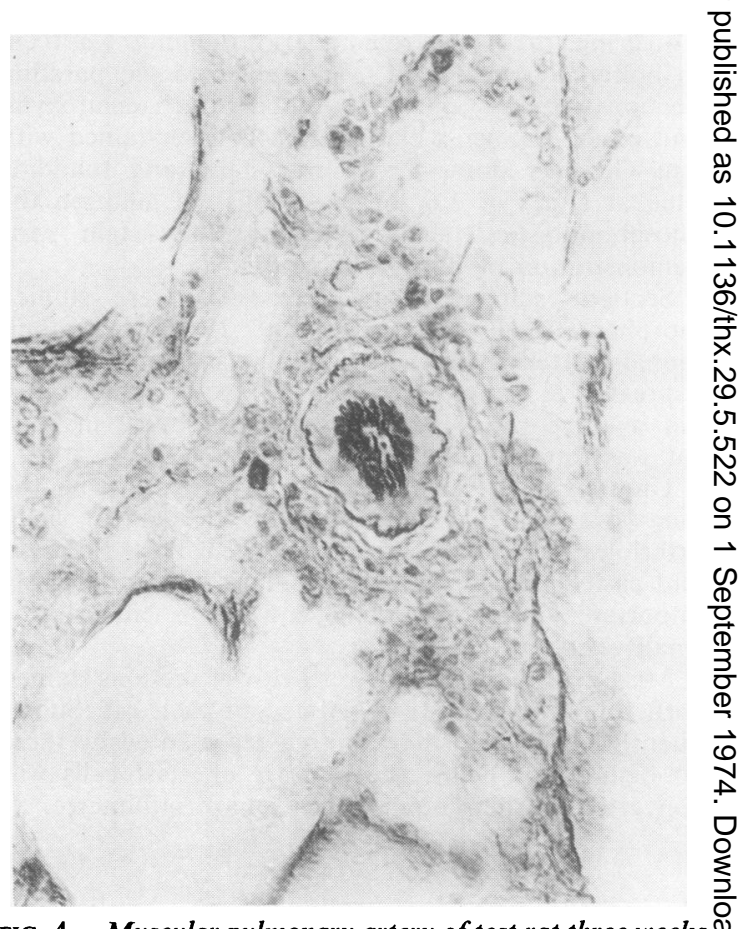

FIG. 4. Muscular pulmonary artery of test rat three weeks after fulvine application. There is excessive crenation of $\underset{\perp}{\stackrel{2}{\alpha}}$ internal elastic lamina, thickening of media, and narrowing of the lumen (Elastic van Gieson $\times 350$ ).

In the adventitia of many arteries, particularly官 after three to four weeks, a new layer of smooth muscle cells is formed. From electron microscopic 0 studies (Wagenvoort et al., 1974) we concluded $\underset{x}{\ddot{x}}$ that these developed from fibroblasts. Although $\bar{\sigma}$ these cells are outside the external elastic lamina, in a haematoxylin and eosin stain they seem to be $\delta$ part of the media, forming one thick muscular coat. Only in the elastic stain it appears that parto of this muscular coat is lying in the adventitia.

Fibrinoid necrosis of pulmonary arteries and arterioles, sometimes accompanied by an inflammatory exudate, was observed in none of the nine? rats surviving for up to three weeks and in 32 of $N$ 41 rats surviving for four weeks or longer (Fig. 5). N The lumina of these vessels were usually narrowed 0 or occluded by fibrin (Fig. 6). Distinct arterial intimal fibrosis was uncommon and observed in only three rats, all surviving for six to seven $\stackrel{\oplus}{+}$ weeks (Fig. 7).

The pulmonary veins and venules normally have

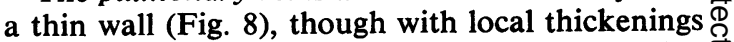
as a result of fibromuscular pads. After fulvine $\mathbb{\otimes}$ application the walls of the veins but particularly of venules showed marked thickening. This was 


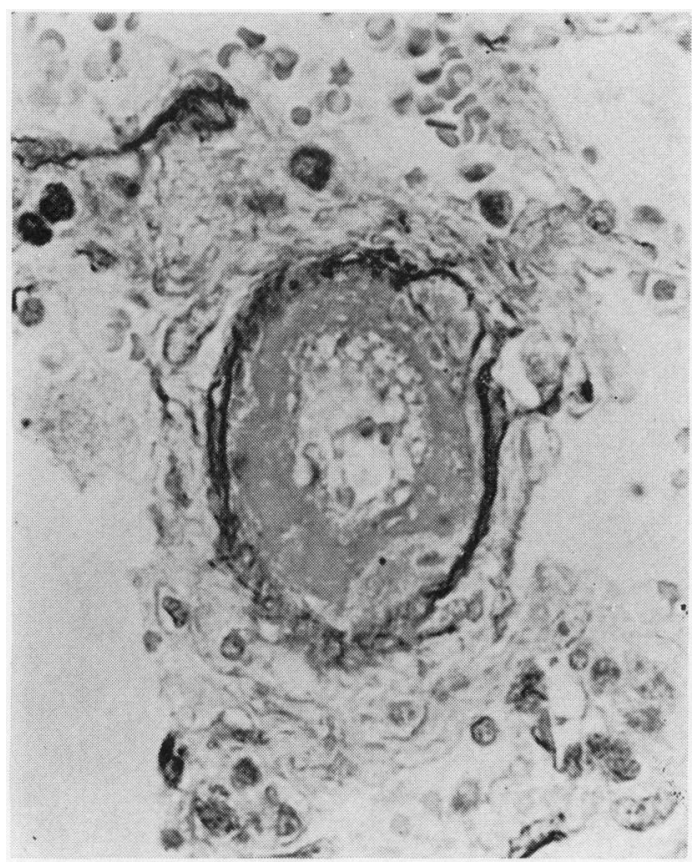

FIG. 5. Muscular pulmonary artery of test rat six weeks after fulvine application. The internal elastic lamina is for the greater part destroyed. This vessel was traced serially to an easily recognizable artery (Elastic van Gieson $\times 550$ ).

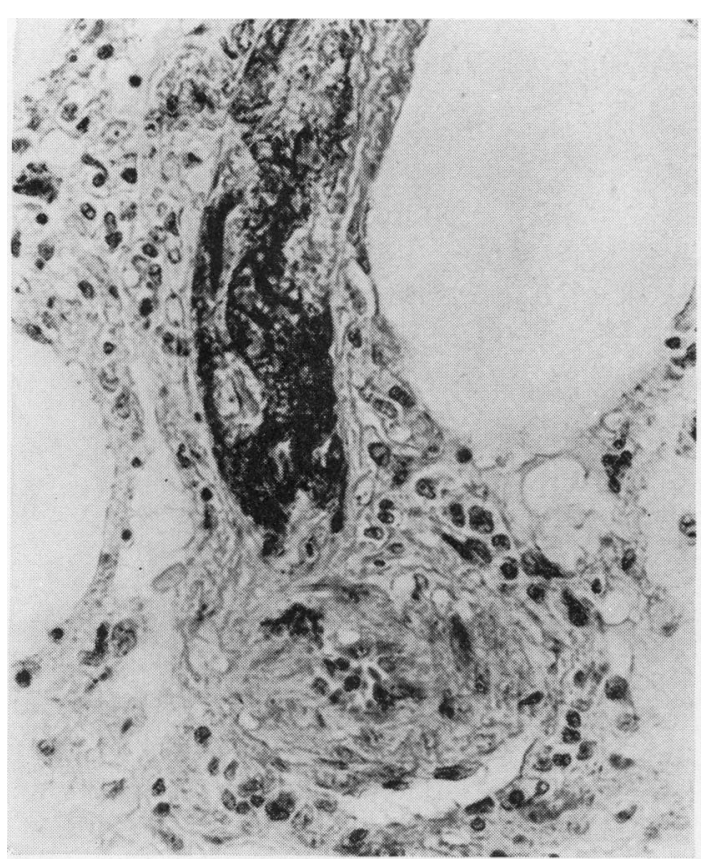

FIG. 6. Muscular pulmonary artery of test rat six weeks after fulvine application, with medial hypertrophy (right) and branch with fibrinoid necrosis and fibrin clot in the lumen (Phosphotungstic acid haematoxylin $\times 350$ ).

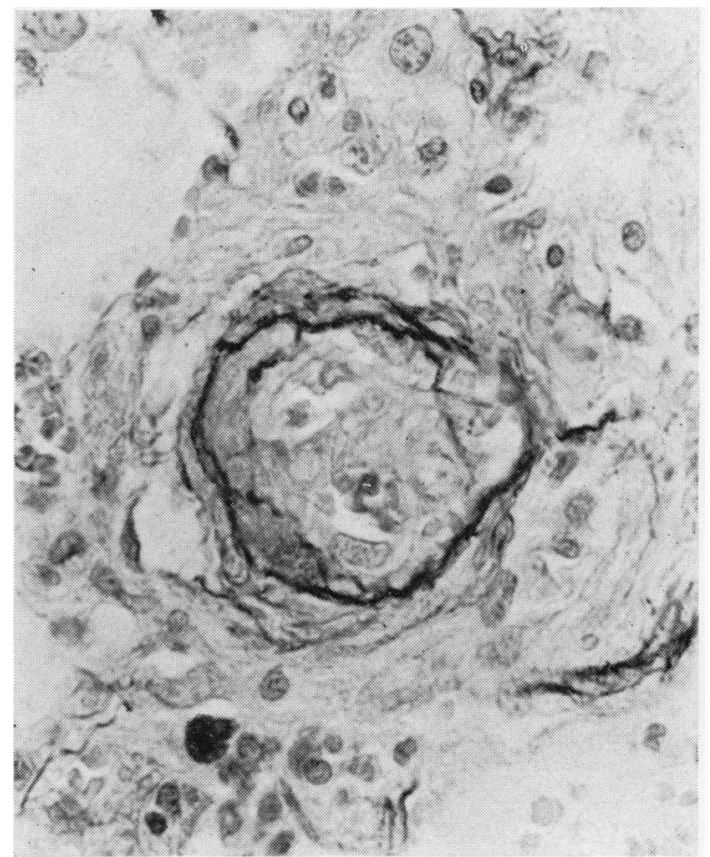

FIG. 7. Muscular pulmonary artery of test rat six weeks after fulvine application. The internal elastic lamina is partly destroyed. The vessel is obliterated by proliferating cells and collagen (Elastic van Gieson $\times 550)$.

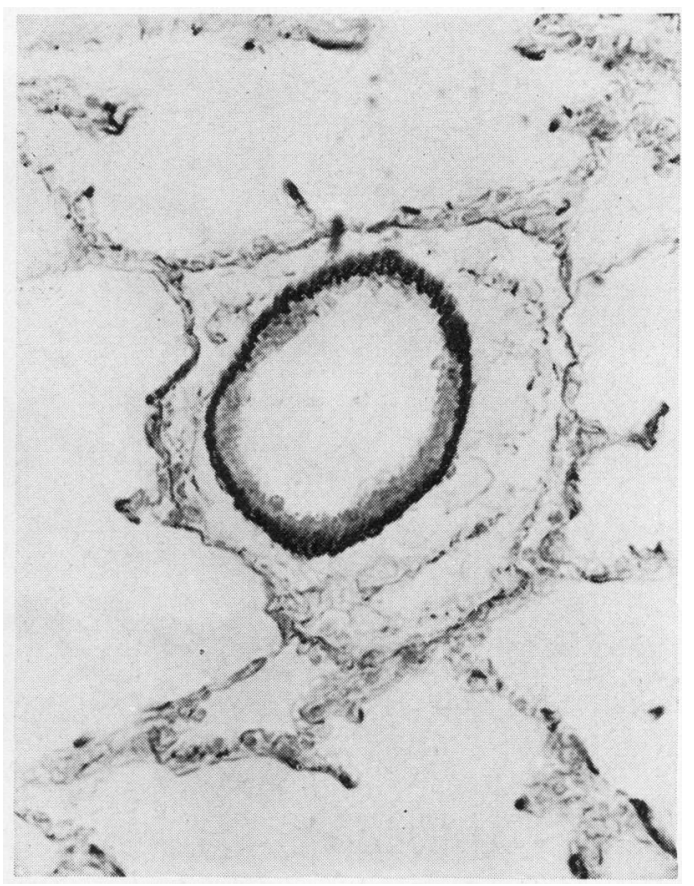

FIG. 8. Normal pulmonary vein of control rat. There is a single elastic lamina. Under the endothelium there is some collagen and an occasional smooth muscle cell (Elastic van Gieson $\times 350$ ). 


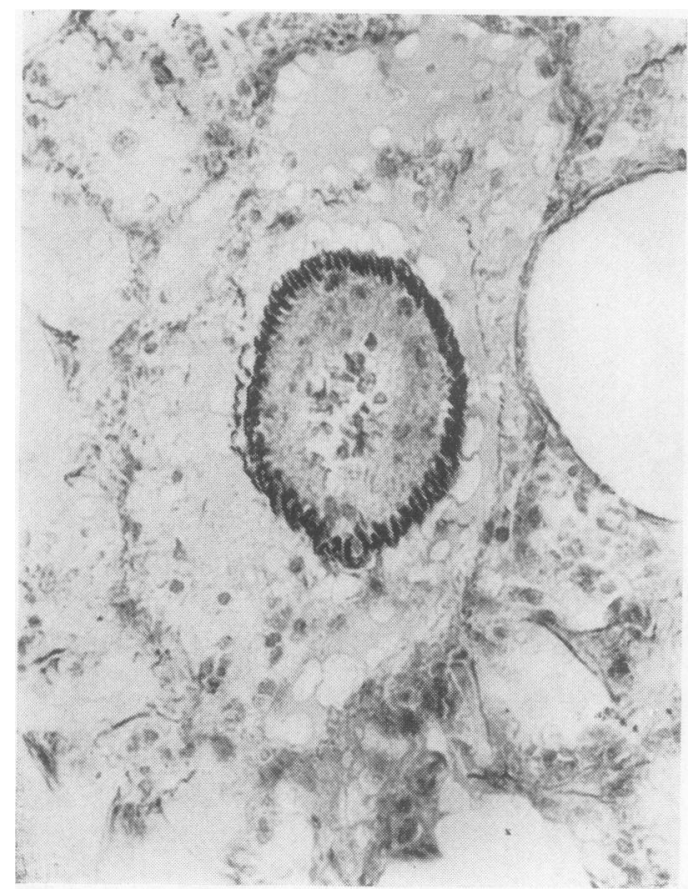

FIG. 9. Pulmonary vein of test rat six weeks after fulvine application. There is excessive crenation of the elastic lamina and increase of smooth muscle cells and collagen with narrowing of the lumen (Elastic van Gieson $\times 350$ ).

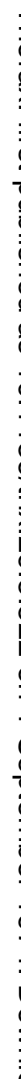

FIG. 10. Portion of wall of pulmonary vein of test rat two weeks after fulvine application. There is infiltration of $\stackrel{\circ}{\Phi}$ the wall by mononuclear inflammatory cells and one mitosis in the endothelium (Haematoxylin and eosin $\overrightarrow{3}$ $\times 1,400)$.

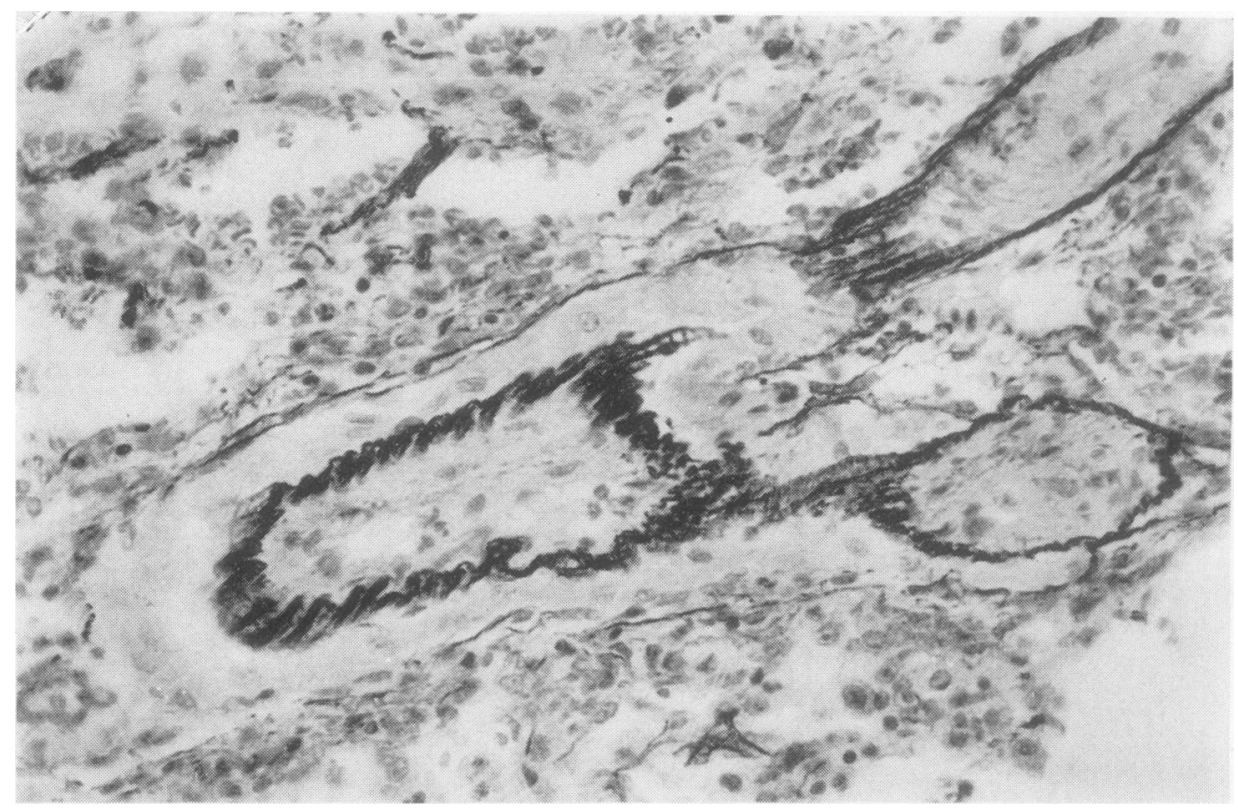

FIG. 11. Large pulmonary vein of test rat six weeks after fulvine application, with a layer of striated muscle cells in its wall and with patchy intimal fibrosis. Two branches without striated muscle are completely obliterated (Elastic van Gieson $\times 350)$. 
already evident one week after the administration of fulvine. In serial sections it appeared that not only were the intimal muscular pads thickened but also the walls in between these pads. This thickening is brought about by proliferation of smooth muscle fibres and increase of collagen. Vasoconstriction of these veins is likely because the single external elastic lamina is markedly crenated as compared to that in normal veins (Fig. 9), while also the nuclei of the muscle fibres were coiled. Proliferation of endothelial cells became apparent and was also evidenced by occasional mitotic activity (Fig. 10). Gradually the venous walls contain more and more collagen in between the muscle cells. This form of thickening of the wall often leads to marked narrowing or obliteration of the veins.

When four or more weeks have elapsed since the beginning of the experiment, some fibrin deposition is noted in the walls of pulmonary venules, but never to the same extent as in arterioles. An inflammatory exudate, particularly of polymorphonuclear cells, is usually present in and around the venous wall. This is also common in the absence of recognizable fibrin deposits.

In 10 rats, distinct patchy intimal fibrosis of venules and also of larger veins (Fig. 11) was observed after four weeks. In these patches no muscle cells could be found.

Although the recognition of small occluded venules and their distinction from small arterioles is sometimes very difficult, by tracing them in serial sections it could be demonstrated that they were tributaries of larger veins, easily recognizable as pulmonary veins, since in rats these have cardiac muscle fibres in their walls.

\section{DISCUSSION}

Since Lalich and Merkow (1961) described that ingestion of the ground seeds of Crotalaria spectabilis by rats produced pulmonary arteritis, several workers have observed the development of right cardiac hypertrophy and medial hypertrophy of muscular pulmonary arteries in similar circumstances (Young, 1962; Turner and Lalich, 1965; Kay and Heath, 1966; Hayashi, Hussa, and Lalich, 1967; Kay et al., 1971). While this suggested pulmonary hypertension, Kay, Harris, and Heath (1967) could actually demonstrate an elevation of right ventricular pressure. With highly toxic concentrations, Stötzer et al. (1972) found an average right ventricular systolic pressure of $62 \mathrm{mmHg}$, even exceeding $100 \mathrm{mmHg}$ in individual cases.
Also, in our experiments with fulvine, pulmonary hypertension was reflected by a gradual increase in right ventricular weight and in medial thickness of the pulmonary arteries and arterioles. It is suggestive that both parameters were already changed within one week following the application of fulvine. The histological appearances of the arteries were entirely compatible with vasoconstriction in view of the extreme narrowing of the vessels and marked crenation of the internal elastic lamina as compared to control rats. It was also borne out by the results of our electron microscopic studies in these cases (Wagenvoort et al., 1974). Probably vasoconstriction is induced very soon after the drug is applied. It must be pointed out that the average medial thickness in our control rats was greater than in those described by Kay et al. (1971). In their material, however, the lungs were distended by formalin, which causes also distension of the blood vessels, whereas we used collapsed lungs.

Fibrinoid necrosis and pulmonary arteritis are likely to be induced by a sudden and severe rise in pressure (Wagenvoort, 1959; Kay and Heath, 1966). In our experiments it occurred in $64 \%$ of all test rats and even in $78 \%$ of the rats surviving for four weeks or more. This incidence is higher than that found by others. Kay and Heath (1969), in their review of the literature, reported it to vary from 13 to $34 \%$. The appearances of the arteries suggested that there was not only deposition of fibrin in the media but that there was also actual disintegration and necrosis of the muscle fibres.

So far significant lesions in the pulmonary veins and venules, resulting from the administration of Crotalaria seeds or their alkaloids, have not been described. Kay and Heath (1966) and Smith, Kay, and Heath (1970) found a suggestion that the normally occurring muscular intimal pads were increased in thickness but they could not make an objective assessment to verify this impression. Barnes, Magee, and Schoental (1964) described an exudate of polymorphonuclear cells around arteries and veins.

In our material lesions in the pulmonary veins and venules were common.

Thickening of the venous wall with signs of vasoconstriction and gradual proliferation of muscle cells were probably present after only one week but certainly after two weeks. Eventually it often leads to severe narrowing of the vascular lumen. This we consider to be a counterpart of the contraction and medial hypertrophy observed in the arteries. The gradual obliteration of the 
pulmonary veins may begin with thickening of the normally occurring muscular intimal pads, as suggested by the observation of Kay and Heath. Eventually, however, there is a continuous thick intimal layer, from an increase of muscle cells and collagen and of endothelial cells, without any indications of these intimal pads. Also, the intimal fibrosis of the larger veins, which normally are devoid of intimal pads, proves that the pulmonary venous changes cannot be regarded merely as hypertrophy of these pre-existent structures.

Fibrin deposition in the venous walls did occur after four weeks, although not to the same degree as in arterial walls. With light microscopy necrosis could not be detected with certainty.

It seems likely that fulvine or its derivatives produces an angiotoxic effect on the smooth muscle fibres of both arteries and veins and possibly on the endothelium as well. That fibrinoid necrosis and pulmonary arteritis came much later than contraction and medial thickening would be consistent with what is known from human cases of pulmonary hypertension, where a similar sequence is observed. As is shown in Fig. 2, there is distinct medial hypertrophy and right ventricular hypertrophy after three to four weeks, but this is preceded by a gradual increase in medial thickness and right ventricular weight in the first two weeks. This suggests that these processes have already begun in the first week and that there is not a distinct latent period between the administration of fulvine and the appearance of vascular lesions, as claimed by Kay et al. (1971). Their supposition that fulvine is not a toxic substance itself but that it may be dehydrogenated in the liver so that reactive pyrroll derivatives are produced and transported to the lungs may well be correct, but in that case this process evolves apparently rather quickly.

The role of mast cells in fulvine intoxication is still undecided. Our studies indicate that the rise in the number of mast cells is phenomenal and that it practically always begins at approximately the fourth week after administration of fulvine. This appeared to be true for rats in poor condition at that time but was equally true for animals which, seemingly healthy, were sacrificed at four weeks. On the other hand, weight loss of the test animals usually sets in at the fourth week, apart from a transient weight loss during the first week which may be related to liver damage. Therefore the assumption of Kay and Heath (1969) that the increased number of mast cells is an expression of non-specific exudative lesions connected with the onset of congestive cardiac $\frac{\bar{C}}{\bar{C}}$ failure cannot be disproved but deserves further $\frac{\bar{\sigma}}{\mathrm{c}}$ study.

The finding that the pulmonary veins and $\stackrel{\mathbb{D}}{\circ}$

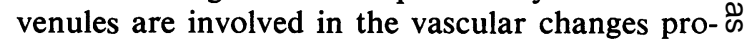
duced by fulvine is of interest, since the first $\vec{\circ}$ vascular effects of Crotalaria alkaloids were described in the veins of the liver. Bras et al. $\vec{\omega}$ (1957) and Bras and McLean (1963) demon- $\frac{\mathscr{\rho}}{\vec{*}}$ strated that pyrrolizidine alkaloids from Crotalaria $\times$ plants, contained in so-called 'bush-tea', were the ${ }_{0}$ cause of veno-occlusive disease of the liver in ir Jamaica and other West Indian countries. In these instances, however, the venous changes have been ${ }_{0}^{N}$ described as due to organizing thrombus. Also, in the rare cases of veno-occlusive disease of the $\vec{c}$ lung the obstruction of the pulmonary veins and $\mathbb{D}$ venules is the result of thrombosis. Moreover, a $\underset{\mathbb{\Phi}}{ }$ dietary factor has not yet been demonstrated in 3 these patients and the available evidence rather足 suggests an infectious aetiology (Wagenvoort, $\overrightarrow{0}$
1972).

The simultaneous involvement of the pulmonary arteries and veins may well detract from theo usefulness of fulvine, and possibly of other Cro-talaria alkaloids, as a model for pulmonaryo arterial hypertension (Stötzer et al., 1972; Chesney and Allen, 1973) as the haemodynamics in a lung in which there is obstruction of both pulmonary $\overrightarrow{\vec{O}}$ arteries and veins are exceedingly complicated.

\section{REFERENCES}

Barnes, J. M., Magee, P. N., and Schoental, R. (1964). Lesions in the lungs and livers of rats poisoned with the pyrrolizidine alkaloid fulvine and its $N$-oxide. Journal of Pathology and Bacteriology, 88, 521 .

Bras, G., Berry, D. M., and György, P. (1957). Plants as aetiological factor in veno-occlusive diseaseo of the liver. Lancet, 1, 960.

and McLean, E. (1963). Toxic factors in veno $=$ occlusive disease. Annals of the New York Academy of Science, 111, 392.

Chesney, C. F. and Allen, J. R. (1973). Animal modeh of human disease: cardiopulmonary disease. N American Journal of Pathology, 70, 489.

Hayashi, Y., Hussa, J. F., and Lalich, J. J. (1967) Cor pulmonale in rats. Laboratory Investigation 16, 875.

Kay, J. M., Harris, P., and Heath, D. (1967). Pul $\stackrel{\mathbb{N}}{?}$ monary hypertension produced in rats by ingestion of Crotalaria spectabilis seeds. Thorax 22, 176. monary arteries and heart weight of rats fed on $\stackrel{?}{\mathbb{Q}}$ Crotalaria spectabilis seeds. Journal of Pathologyto and Bacteriology, 92, 385. 
- and (1969). Crotalaria spectabilis. The Pulmonary Hypertension Plant. Thomas, Springfield, Illinois.

,$- \frac{}{2}$, Smith, P., Bras, G., and Summerell, J. (1971). Fulvine and the pulmonary circulation. Thorax, 26, 249.

Lalich, J. J. and Merkow, L. (1961). Pulmonary arteritis produced in rats by feeding Crotalaria spectabilis. Laboratory Investigation, 10, 744.

Smith, P., Kay, J. M., and Heath, D. (1970). Hypertensive pulmonary vascular disease in rats after prolonged feeding with Crotalaria spectabilis seeds. Journal of Pathology, 102, 97.

Stötzer, H., Herbst, M., Reichl, R., and Köllmer, H. (1972). Zur Pathogenese der experimentellen pulmonalen Hypertonie. Virchows Archiv, Abteilung A, Pathologische Anatomie, 356, 331.

Turner, J. H. and Lalich, J. J. (1965). Experimental cor pulmonale in the rat. Archives of Pathology, 79, 409.

Wagenvoort, C. A. (1959). The morphology of certain vascular lesions in pulmonary hypertension. Journal of Pathology and Bacteriology, 78, 503.

(1972). Vasoconstrictive primary pulmonary hypertension and pulmonary veno-occlusive disease. Cardiovascular Clinics, 4, 97.

—, Dingemans, K. P., and Lotgering, G. G. (1974). Electron microscopy of pulmonary vasculature after application of fulvine. Thorax, 29, 511.

Young, D. E. (1962). Cardiovascular lesions in rats fed Crotalaria spectabilis. Federation Proceedings, 21, 273.

Requests for reprints to: Professor C. A. Wagenvoort, Department of Pathological Anatomy, Wilhelmina Gasthuis, University of Amsterdam, The Netherlands. 